\title{
Selection in highly inbred populations of Drosophila melanogaster polymorphic at a single locus*
}

\author{
Rodolfo Costa ${ }^{1}$, Loredana Nigro', \\ Viviana Cambissa ${ }^{1}$, \\ Suresh D. Jayakar', \\ Laura Zonta ${ }^{2}$, John A. Beardmore
}

\author{
${ }^{1}$ Department of Biology, University of Padova, via \\ Loredan 10, 35100 Padova, Italy; \\ 2 The "A. Buzzati-Traverso" Department of Genetics \\ and Microbiology, University of Pavia, via S. Epifanio \\ 14, 27100 Pavia, Italy; \\ ${ }^{3}$ Genetics Department, University College of Swansea, \\ Singleton Park, Swansea SA2 8PP, UK.
}

\begin{abstract}
The polymorphic Esterase-6 system in Drosophila melanogaster has been studied in laboratory populations made up from highly inbred lines. The $E s t-6^{S}$ and $E s t-6^{F}$ homozygous lines were obtained after 100 generations of inbreeding, selecting heterozygotes at each generation. The level of homogeneity in the genetic background of the lines has been estimated by computer simulation of the inbreeding process and confirmed by electrophoresis. The experimental populations were cultured on a control medium and on media containing different concentrations of naturally occurring esters known to be rapidly utilised by Esterase-6. The results indicate significant genotype-environment interactions. The high level of genetic homogeneity of the lines and the specific pressure applied to the locus analysed suggest that the fitness effects observed could be reasonably attributed to Est-6 allozymes.
\end{abstract}

\section{INTRODUCTION}

Evidence of selection acting at the single locus level is so far scarce. Sincle locus selection is generally undetectable due to the impossibility of excluding interactions with possible effects of the genetic background on the fitness. Linkage disequilibrium between the locus scored and other loci linked to it could underlie many experimental results which apparently indicate selection at a specific single gene-enzyme polymorphic system. Franklin and Lewontin (1970), on the basis of theoretical models mainly dealing with single locus overdominance, suggested that disequilibrium could be quite common between closely linked loci in natural populations. Nevertheless, subsequent experimental approaches revealed that this is difficult to demonstrate, especially when the population size is large, and that linkage equilibrium seems indeed to be widespread in the systems scored. Of course, breeding systems are of importance: strong linkage disequilibrium has been found in predominantly self-fertilising plants (Allard, Kahler and Weir, 1972; Kahler, Clegg and Allard,

\footnotetext{
* This paper is dedicated to Professor Giuseppe Montalenti on the occasion of his 80 th birthday.
}

1975; Allard, 1975) whilst, among the relatively few successful surveys of linkage disequilibrium in outcrossing species, significant disequilibrium has been found in man at very closely linked loci (i.e., within a map unit), namely for $\beta$ and $\delta$ hemoglobin polypeptides (Boyer et al., 1963) and in the HLA system (Thorsby, 1974). In Drosophila, weak disequilibrium or even equilibrium has been most frequently found even with closely linked loci (Kojima, Gillespie and Tobari, 1970; Mukai, Mettler and Chigusa, 1971; Charlesworth and Charlesworth, 1973; Langley, Tobari and Kojima, 1974; Mukai, Watanabe and Yamaguchi, 1974; Langley, Ito and Voelker, 1977; Mukai and Voelker, 1977; Langley, Smith and Johnson, 1978; Charlesworth et al., 1979; Loukas, Krimbas and Vergini, 1979; Trippa et al., 1978; Loukas, Krimbas and Morgan, 1980; Cabrera et al., 1983). In order to circumvent the problems arising in experiments devoted to demonstrating selective phenomena (if any) associated with an electrophoretically polymorphic locus, three approaches have been suggested: (1) the choice of "environmental conditions" exerting a specific pressure on the function(s) of the enzyme analyzed (i.e., addition of excess substrate(s) to the medium) (Gibson, 1970; Wills and Nichols, 1971; De Jong and Scharloo, 
1976; Cavener and Clegg, 1978; Danford and Beardmore, 1980; Bijlsma and Kerver, 1983; Powell and Andjelkovic, 1983), (2) the use of inbred lines in order to reduce the effects of heterogeneity in the genetic background and to amplify the relative contribution (if any) to the fitness of the locus under investigation (Wills and Nichols, 1971; Wills, Phelps and Ferguson, 1975), (3) the selection for or against a physiological enzymatic function by using techniques analogous to those applied in selecting auxotrophic mutants in bacteria (Powell and Andjelkovic, 1983).

The Est-6 locus in Drosophila melanogaster is a structural gene for a carboxylesterase (E.C.3.1.1.1.), polymorphic in wild populations with two frequent alleles, Est- $6^{S}$ and Est-6 ${ }^{F}$ (Wright, 1963; Girard, Palabost and Petit, 1977; Danieli and Costa, 1977; Oakeshott et al., 1981; Triantaphyllidis et al., 1982) and with latitudinal clines, the frequency of Est $-6^{F}$ being highest at the equator and decreasing with latitude in both hemispheres (Anderson and Oakeshott, 1984). The Est-6 locus maps in the left arm of the third chromosome at $36.8 \mathrm{cM}$. This polymorphism has been studied in laboratory populations with a variety of approaches by many workers. Evidence for selection mainly dependent on frequency, temperature and density, and involving the chromosomal regions carrying genetic variability for the Est-6 locus has been produced (MacIntyre and Wright, 1966; Kojima and Yarbrough, 1967; Birley and Beardmore, 1977; Costa and Beardmore, 1980; Gilbert and Richmond, 1982). Moreover, it has recently been demonstrated that the Esterase- 6 allozymes are involved in reproductive processes (Richmond et al., 1980); Esterase-6 seems to influence female productivity and the timing of subsequent remating (Gilbert, Richmond and Sheehan, 1981 $a$, $b$; Gilbert and Richmond, 1981; Richmond and Senior, 1981).

Danford and Beardmore (1980) analysed the effects of naturally occurring esters, already known to be very rapidly utilised by Esterase-6 (Danford and Beardmore, 1979), by adding them to the medium at concentrations much higher than those normally found in the wild (Hulme, 1970). They used polymorphic populations set up with outbred lines monomorphic for Est $-6^{S}$ and Est $-6^{F}$ alleles derived from a Groningen population. They observed that the genotypes differed in their response to additives in laboratory conditions even if they could not exclude effects of closely linked loci.

Here we report results concerning the possible involvement of the Est-6 locus of Drosophila melanogaster in selective processes. In our experiments we adopted two of the above "circumventing conditions": (1) the use of experimental populations constructed with different genotypic compositions at the Est-6 locus from iines which have been made homogeneous in their genetic background by 100 generations of inbreeding, (2) the addition to the medium of different concentrations of two esters, $n$-propylformate ( $n$-PF) and methylmalonate $(\mathrm{MM})$, producing significant effects in the output genotype ratios in outbred populations (Danford and Beardmore, 1980).

\section{MATERIALS AND METHODS}

\section{Inbred lines and computer simulation of the inbreeding process}

The inbred lines used in the experiments reported here have been obtained by the mating scheme shown in table 1. As can be seen the Est-6 locus (locus 1) was kept heterozygous at each generation during the inbreeding. All other loci examined electrophoretically (ADH, PGI, Hex-C, GOT-1, GOT-2 on chromosome II and PGM, SOD, IDH, Est-C, ODH, Aph, Acph-1 on chromosome III) were monomorphic for the same allele in both lines; also the total protein pattern showed no

Table 1 Procedure used to obtain the inbred lines used for the experiments

1) Starting from two homozygous stocks for Est- $6^{S}$ and Est- $6^{F}$ alleles derived from a population sampled in Groningen (the Netherlands), 20 crosses were set up; $10 \% S / S \times \& F / F$ and $10 \% F / F \times \delta S / S$.

2) Virgins were collected and 20 crosses $S / S \times S / F$ were set up.

3) Virgins were collected from the progeny of the 10 most active crosses and 40 blind crosses were set up.

4) Parents were typed and only the progeny of $S / F \times S / F$ was used for the next crosses.

5) Up to the 100 th generation of inbreeding 40 crosses were set up at cach generation, alternating cousin $\times$ cousin crosses and brother $\times$ sister crosses every other generation. Flies from the 4 fittest $S / F \times S / F$ crosses were always used.

6) The cousin crosses were set up according to the following scheme

$\begin{array}{lllll} & \mathrm{a} & \mathrm{b} & \mathrm{c} & \mathrm{d} \\ \operatorname{coss} n & \delta \mathrm{a} \times q \mathrm{~b} & \delta \mathrm{b} \times q \mathrm{c} & \delta \mathrm{c} \times q \mathrm{~d} & \delta \mathrm{d} \times q \mathrm{a} \\ \operatorname{cross}+n+2 & \delta \mathrm{a} \times q \mathrm{c} & \delta \mathrm{b} \times q \mathrm{~d} & \delta \mathrm{c} \times q \mathrm{a} & \delta \mathrm{d} \times q \mathrm{~b}\end{array}$

At cross 100 the vials with progeny were mixed and kept in culture bottles. After 4-5 generations, one Est-6 S/S and one $F$ st $-6 F / F$ homozygous lines were extracted by making single pair matings at random and typing the parents when first or second instar larvae were observed.

8) After 15 gencrations from cross 100 other $2 \mathrm{Est}-6 \mathrm{~S} / \mathrm{S}$ and $4 E s t-6 F / F$ not independently derived lines were obtained and used for experiments. 
variability between lines. Furthermore, all Xlinked loci tested were monomorphic (Fum, Hex$A$, G6PD, 6PGD), which suggests homogeneity for genes responsible for the regulation of Est-6 activity which are known to be on the X-chromosome (Tepper et al., 1982; 1984). In order to estimate the probability that a hypothetical second locus (locus 2) would remain polymorphic at the end of the inbreeding process (generation 100), we resorted to computer simulations using a pseudorandom number generator. These simulations were carried out for different distances between the two loci, and for three initial gene frequencies at locus 2. The same simulations were repeated assuming heterosis at locus 2 with the homozygotes equally fit. Two different values of homozygote fitness were used, 0.9 and 0.99 . Further, the effect of starting with the two loci in complete linkage disequilibrium was also analysed, i.e., the runs were started with all Est $-6^{S}$ chromosomes having one allele at locus 2 and all the Est $-6^{F}$ chromosomes the other.

In each simulated run, the chromosomes of each individual of four mating pairs were assigned independently with the restriction that each individual was heterozygous at the Est-6 locus. The alleles at locus 2 were either (i) assigned at random using a given gene frequency or (ii) in the case of linkage disequilibrium, were determined by the Est-6 locus. At every generation the following procedure was adopted. A male and a female of genotype Est $-6^{\mathrm{S}} /$ Est $-6^{F}$ were chosen at random from the offspring of one of the above crosses, and this was repeated so as to have four Est $-6^{\mathrm{S}} /$ Est $^{-6^{F}}$ pairs. The mating pairs for the next generation were formed following the inbreeding scheme shown in table 1 . At each generation a check was carried out to see whether there was still variation at locus 2. As soon as one allele was fixed at locus 2 , the run was terminated, and the generation number recorded. The run was stopped after 100 generations if no fixation had occurred at locus 2 . For several values of the map distance, the probability of non-fixation and the mean number of generations to fixation were estimated for each combination of the other parameters on a total of 500 runs.

\section{Design of experiments}

An initial experiment was intended as a comparison with that of Danford and Beardmore (1980) for outbred lines. The lines were cultured at $25^{\circ} \mathrm{C}$ on a sucrose-yeast medium (Mittler and Bennet, 1962). Two treatments were used: a control and one with the addition of $0.02 \mathrm{M} n$-PF to the culture medium. The density used was 20 fertilised females per bottle and the genotype input ratios were $1: 4,1: 1$ and $4: 1$ of SS:FF.

The emerging flies were collected for 5 days, counted, sexed and kept at $24^{\circ} \mathrm{C}$ for 4 days and then stored at $-30^{\circ} \mathrm{C}$ until the electrophoretic assay was performed. The results of this experiment were mostly negative. The only important indication was that there were significant selective differences between the sexes. In order to amplify any selective effects that might exist, two further experiments were planned. The most relevant differences with respect to the former experiment were the increased densities of females per bottle, the higher concentrations of esters and the presence of heterozygotes among the emerging progeny. In experiment I three different genotypic ratios of 4-5 day old Est $-6^{S} /$ Est $-6^{S}$ and Est $-6^{F} /$ Est $-6^{F}$ females fertilized by males of the same genotype were used $(1: 4 ; 1: 1 ; 4: 1)$. Experiment II was planned so as to have all three genotypes among the progeny at three different frequencies of Est- $6^{s}(0 \cdot 3 ; 0 \cdot 5 ; 0.7)$ and in Hardy-Weinberg proportions. The heterozygotes were the progeny of SS $\times$ FF or FF $\times$ $\mathrm{SS}$ crosses in equal proportions.

One hundred inseminated females per bottle were used. Three replicates of controls and treated cultures were set up for each combination. The esters $n$-propylformate ( $n$-PF) and methylmalonate (MM) (from Sigma Chem. Comp.) were added to the medium following the procedure of Danford and Beardmore (1980). In experiment I 0.03 M $n$-PF and MM were used, and 0.05 M n-PF and MM in experiment II. The $q q$ were allowed to lay eggs for 4 days and then discarded. As the Fl individuals emerged they were collected daily for 14 days and stored as above. The analyses of the data were carried out using discrete multivariate techniques and log linear models (Gokhale and Kullback, 1978).

\section{Electrophoretic analysis}

About 50 flies per sex were assayed from each replicate to estimate genotypic frequencies. The sample was made up of flies proportional in number to those emerging on each day, so that possible effects due to different developmental times of the different genotypes were minimised. Electrophoresis was carried out using 6 per cent vertical slab polyacrilamide gels. Gels, buffers and staining procedure were as previously reported (Costa and Beardmore, 1980). 


\section{RESULTS}

\section{Computer simulations}

Fig. 1a shows the estimated probabilities of polymorphism with recombination frequency, and fig. $1 b$ that of the mean number of generations to fixation. This mean is calculated with the distribution truncated at 100 generations. The graphs in these two figures are similar in shape. As expected, both estimates increase as the gene frequencies at locus 2 come closer to $p=0 \cdot 5$. Further, the introduction of complete linkage disequilibrium between the two loci at the beginning of the process increases both estimates considerably. Figs. $2 a$ and $2 \mathrm{~b}$ show the corresponding graphs with selection against the two homozygotes. A comparison of these with figs. $1 \mathrm{a}$ and $\mathrm{lb}$ shows that this difference in fitness affects the results only slightly. Only results for homozygote fitnesses $=0.9$ (relative to
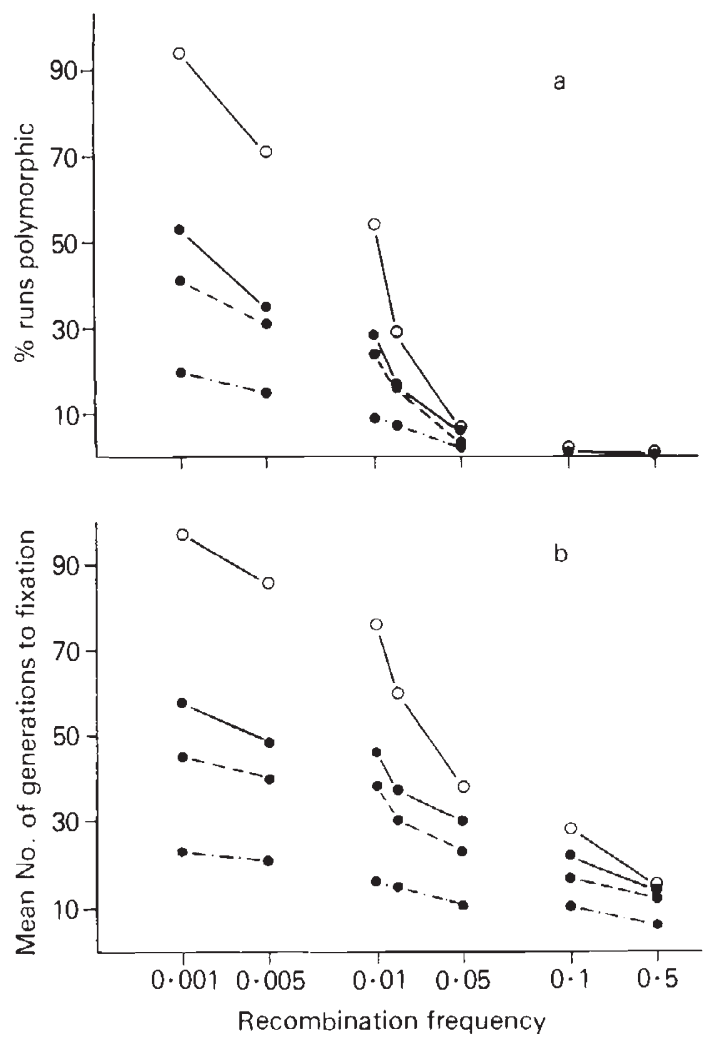

Figure 1 Variation of estimates of (a) probability of persistence of polymorphism and $(h)$ mean number of generations to fixation with recombination frequency in the absence of selection. Initial gene frequencies at locus 2

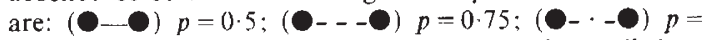
0.9 ; simulation with complete initial linkage disequilihrium is $(0-0)$.
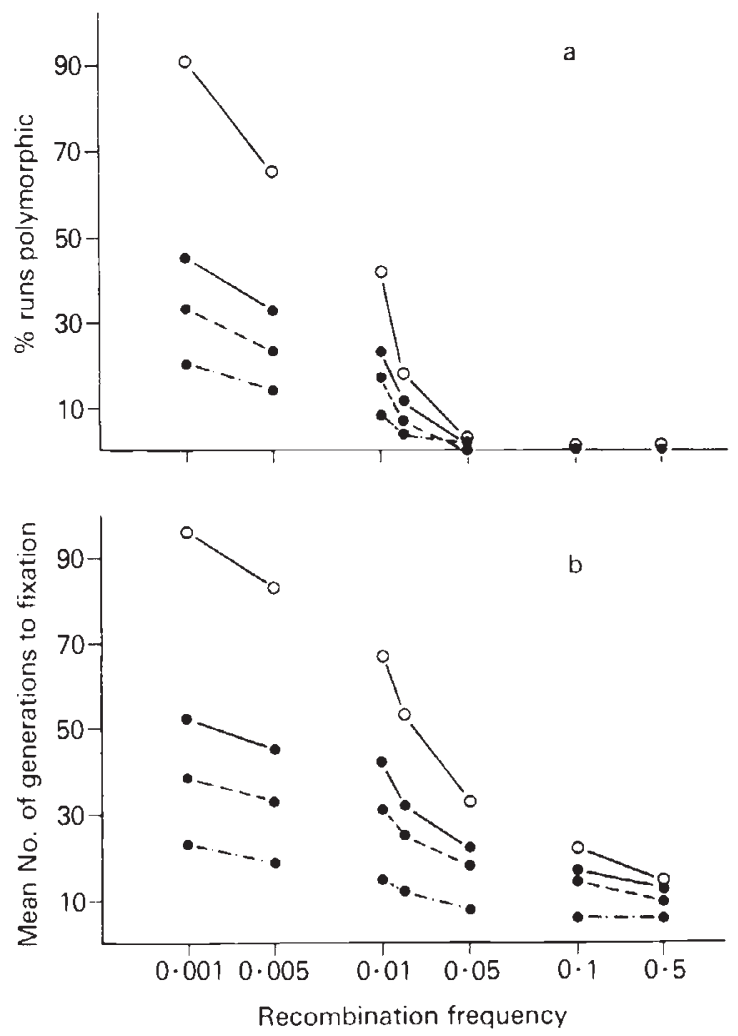

Figure 2 Same as fig, 1 with homozygote fitnesses $=0.9$ relative to heterozygote. See legend to fig. 1.

heterozygote) are reported since for fitness $=0.99$ the differences were not significant.

\section{Effects of gene frequencies and esters on the numbers and compositions of the output}

In three out of 36 combinations there was a significant difference between replicates at the 5 per cent level of significance. This result, or a more extreme one, would be expected by chance with a probability of 0.40 . We decided then to pool the results of the replicates. Table 2 shows the yields in the two experiments, i.e., the total number of eclosions. Those for the control of Experiment I are unavailable due to technical difficulties. In the Controls the highest yield was for the input $p(S)=$ 0.5 as would be expected if the genotypes differ in their use of nutritional recources. From table 2, it can be seen that the addition of MM reduces the yield significantly at both concentrations $\left(G_{[1]}^{2}=38.9\right.$, Expt. I; $G_{[1]}^{2}=116.2$, Expt. II ; $P<$ $0.001)$ with respect to $n$-PF. This reduction is seen also in comparison with the control, as also reported by Danford and Beardmore (1980). On the 
Table 2 Yields for the experiments

\begin{tabular}{lllll}
\hline Expt. & $\begin{array}{l}\text { Input } \\
\text { ratio }\end{array}$ & $\begin{array}{l}\text { Control } \\
\text { yield }\end{array}$ & $\begin{array}{l}n \text {-PF } \\
\text { yield }\end{array}$ & $\begin{array}{l}\text { MM } \\
\text { yield }\end{array}$ \\
\hline I & $1: 4$ & - & 558 & 417 \\
& $1: 1$ & - & 562 & 493 \\
& $4: 1$ & - & 642 & 501 \\
I1 & 0.3 & 582 & 720 & 416 \\
& 0.5 & 679 & 528 & 423 \\
& 0.7 & 555 & 533 & 356 \\
\hline
\end{tabular}

The input ratio refers to SS:FF in experiment $I$ and to the frequency of $S$ in experiment II.

other hand the addition of $n$-PF does not show a significant difference with respect to the control $\left(G_{[1]}^{2}=0.34 ; P>0.50\right)$. Tables 3 and 4 show the genotypic output in the two experiments and their analyses. The values of $G^{2}$ shown in these tables are derived from a factorial analysis. The main effects of treatment and sex and their interaction were never significant. All other effects and interactions are reported in these tables with their significance levels. The fitnesses shown are relative to the Est $-6^{F} /$ Est $-6^{F}$ genotype and the allelic fitnesses in table 4 are relative to the Est $-6^{F}$ allele. These relative fitnesses are plotted in fig. 3. We will discuss the results of each experiment separately.

In experiment I (table 3 ) although only one of the $G$ (genotypic) effects is significant when all three treatments (control and two esters) are considered, the $G$ effect is also significant both at the $1: 1$ ratio $\left(G_{[1]}^{2}=13 \cdot 3, P<0 \cdot 001\right)$ and at the $4: 1$ ratio $\left(G_{[1]}^{2}=15.7, P<0.001\right)$ if we consider only the data for Control and $n$-PF. The overall $G$ effect

Table 3 Results of Experiment I and their $G^{2}$ analysis

\begin{tabular}{|c|c|c|c|c|c|c|c|c|c|}
\hline \multirow{2}{*}{$\begin{array}{l}\text { Input } \\
S / S: F / F\end{array}$} & & \multicolumn{2}{|l|}{ Control } & \multicolumn{2}{|c|}{$n-\mathrm{PF}(0.03 \mathrm{M})$} & \multicolumn{2}{|c|}{$\mathrm{MM}(0.03 \mathrm{M})$} & \multirow{2}{*}{$\begin{array}{l}G_{[1]}^{2} \\
\mathrm{G}\end{array}$} & \multirow{2}{*}{$\begin{array}{l}G_{[2]}^{2} \\
\mathrm{G} \times \mathrm{T}\end{array}$} \\
\hline & & $\mathrm{S} / \mathrm{S}$ & $\mathrm{F} / \mathrm{F}$ & $\mathrm{S} / \mathrm{S}$ & $F / F$ & $\mathrm{~S} / \mathrm{S}$ & $F / F$ & & \\
\hline $1: 4$ & $\begin{array}{l}M \\
F \\
\text { fitness }\end{array}$ & $\begin{array}{l}30 \\
38 \\
1.092\end{array}$ & $\begin{array}{r}130 \\
119 \\
1\end{array}$ & $\begin{array}{l}33 \\
29 \\
1 \cdot 042\end{array}$ & $\begin{array}{r}119 \\
119 \\
1\end{array}$ & $\begin{array}{l}10 \\
19 \\
0.433\end{array}$ & $\begin{array}{r}135 \\
133 \\
1\end{array}$ & $4.00^{*}$ & $19.44^{* * *}$ \\
\hline $1: 1$ & $\begin{array}{l}M \\
F \\
\text { fitness }\end{array}$ & $\begin{array}{l}67 \\
75 \\
0.934\end{array}$ & $\begin{array}{r}79 \\
73 \\
1\end{array}$ & $\begin{array}{l}42 \\
58 \\
0.565\end{array}$ & $\begin{array}{r}89 \\
88 \\
1\end{array}$ & $\begin{array}{l}76 \\
89 \\
1.320\end{array}$ & $\begin{array}{r}66 \\
59 \\
1\end{array}$ & $2 \cdot 56 \mathrm{~ns}$ & $25 \cdot 00^{* * *}$ \\
\hline $4: 1$ & $\begin{array}{l}M \\
F \\
\text { fitness }\end{array}$ & $\begin{array}{l}111 \\
100 \\
0.723\end{array}$ & $\begin{array}{r}38 \\
35 \\
1\end{array}$ & $\begin{array}{l}100 \\
108 \\
0.642\end{array}$ & $\begin{array}{r}43 \\
38 \\
1\end{array}$ & $\begin{array}{r}119 \\
129 \\
1.550\end{array}$ & $\begin{array}{r}17 \\
23 \\
1\end{array}$ & $3 \cdot 34 \mathrm{~ns}$ & $20 \cdot 08^{* * *}$ \\
\hline
\end{tabular}

The fitnesses are relative to the $\mathrm{F} / \mathrm{F}$ genotype for the same input ratio and the same treatment. $\mathrm{M}$ and $\mathrm{F}$ indicate respectively males and females. $\mathrm{G}=$ genotype; $\mathrm{S}=\mathrm{sex} ; \mathrm{T}=$ treatment.

${ }^{*} P<0.05 ;{ }^{* *} P<0.01 ;{ }^{* * *} P<0.001$.

Table 4 Results of Experiment II and their $G^{2}$ analysis

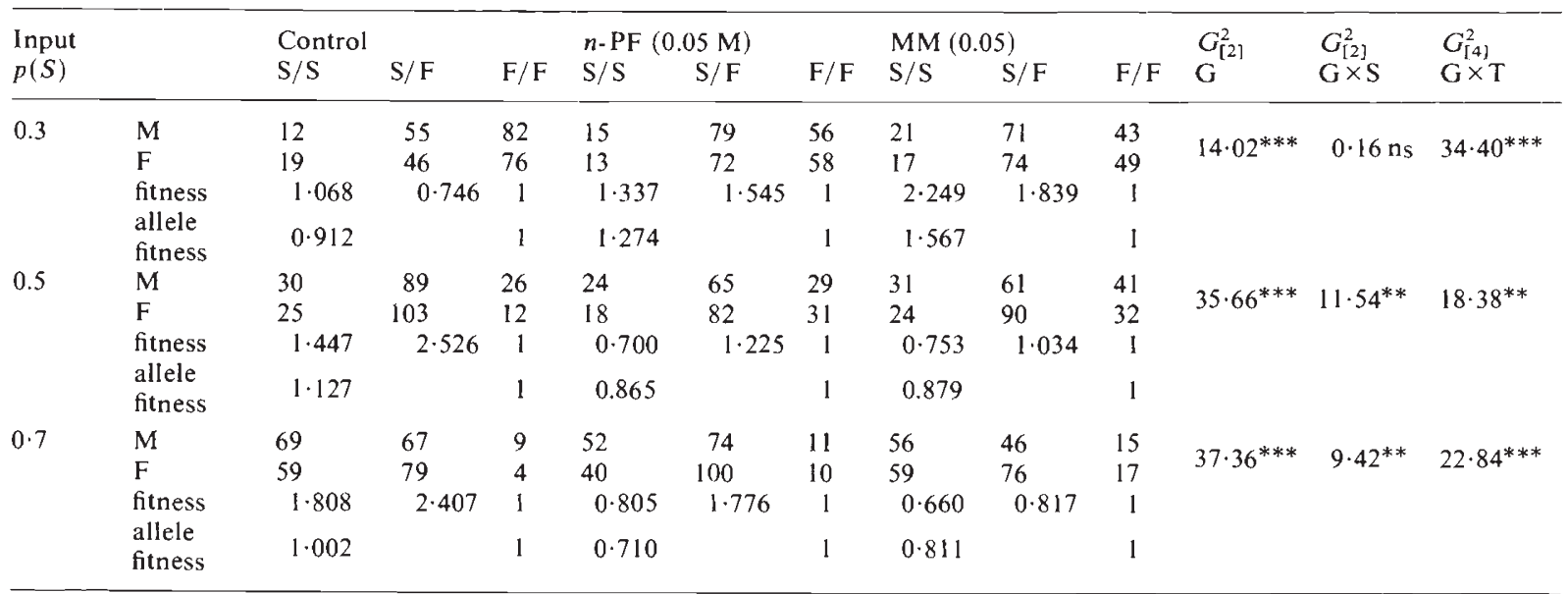

Allele fitnesses are those of $S$ relative to $F$. See also legend to table 3 . 

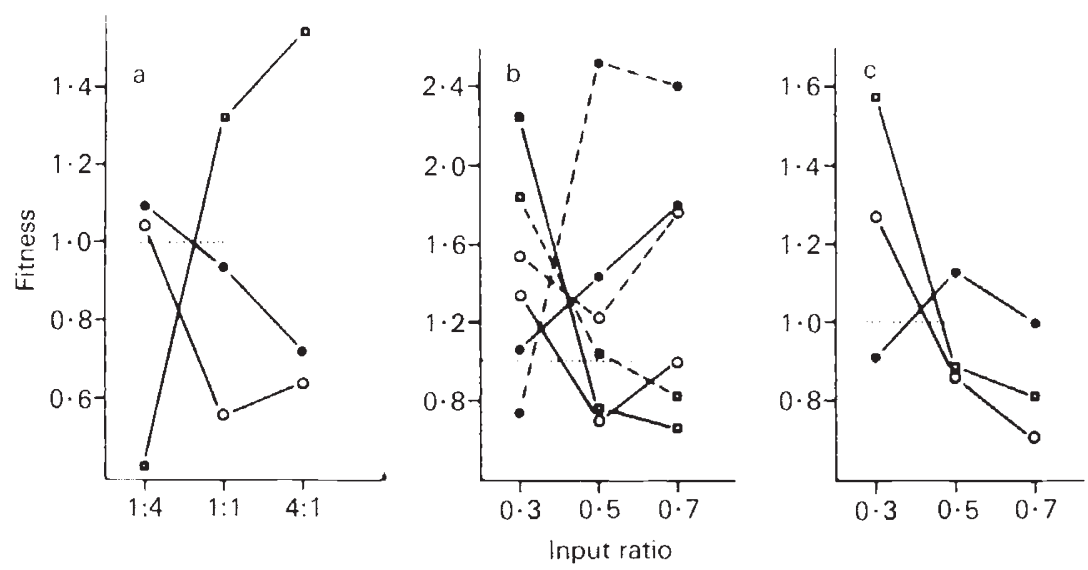

Figure 3 Fitnesses of genotypes $S / S$ and $S / F$ relative to $F / F$, and of allele $S$ relative to $F$ in the three experiments. The horizontal dotted line corresponds to equal fitnesses of the genotypes. (a) Experiment I: (b) Experiment II: genotypic fitnesses; (c) Experiment II: allelic fitnesses. The symbols used are: $(\mathbf{O})=$ Control; $(O)=n-P F ;(\square)=M M ;(-)=$ Genotype $S / S$ or allele $S ;(\ldots)$ genotype $S / F$.

is not significant because selection in the presence of MM goes in the opposite direction (see fig. $3 \mathrm{a}$ ). In fact the interaction $G \times T$ (genotype $\times$ treatment) is highly significant at all ratios. Thus it would seem that in the presence of $\mathrm{MM}$ the fitness of the Est $-6^{\prime} /$ Est $-6^{\prime \prime}$ genotypes is positively correlated with its input frequency.

In experiment II (table 4) the $G$ effect and the $G \times T$ interaction are significant. The $G \times S$ interaction is significant at the 0.5 and 0.7 input gene frequencies. There is then a clear indication of selection which is different for the different treatments and different in the two sexes. The two selective effects which seem most evident, but which do not occur uniformly, are heterosis and frequency-dependence. The frequency-dependence is in favour of the rare allele in the presence of the esters; heterosis is present at the gene frequency of 0.5 and at the gene frequency of 0.7 except when MM is present.

\section{DISCUSSION}

The results obtained demonstrate significant genotype-environment interactions. We planned the experiments in such a way that a specific pressure, relevant to the function of the studied enzyme, was applied to the organisms. It is not possible to completely exclude the possibility that the fitness effects observed can be due to loci other than Est-6 but tightly linked to it. There is also a slight possibility that new mutations have occurred in the genetic background, particularly late in the inbreeding processes, possibly causing persistence of polymorphisms in the inbred lines. Nevertheless in our opinion the changes in the patterns of the Est-6 polymorphism, observed under the experimental conditions adopted, are most probably due to selection at the Est-6 locus. Moreover since we used highly inbred Est $-6^{S}$ and Est $-6^{F}$ homozygous lines to set up the polymorphic populations it seems unlikely that other targets of selection, such as linked gene(s), are involved in the selective phenomena observed. The level of genetic homogeneity obtained after 100 generations of inbreeding was estimated by computer simulation, considering absence or presence of selection as well as complete initial linkage disequilibrium at a hypothetical locus 2 . The results suggest that after 100 generations of inbreeding only linked loci with a recombination rate of less than about 0.05 are likely to remain polymorphic (i.e., they have a probability of more than $0 \cdot 05-0 \cdot 10$ of not being fixed) (see figs. 1 and 2). Moreover, as can be seen from the list of biochemical loci of Drosophila melanogaster by Treat, Doane and MacIntyre (1980), no other Esterase or electrophoretically variable loci capable of interacting with the substrates used for conditioning the media are known to map in that region.

In Drosophila melanogaster, Est-6 activity is affected by regulatory genes on the X-chromosome (Tepper et al., 1982; 1984). The inbreeding process carried out has almost certainly rendered the $\mathrm{X}$ chromosomes in the $S$ and $F$ lines identical, thus excluding differences in regulation between the Est-6 genotypes. 
The selective mechanisms which are apparently operating (heterosis and frequency dependent selection) seem to be influenced, to different degrees, by the genotypic compositions, the kind of treatment and sex. Nevertheless at present it is not clear to us how selection operates. Information about in vivo functions of Est-6 in ester metabolism is still scanty. In vitro biochemical analysis of Est-6 allozymes showed different properties of the variants (Danford and Beardmore, 1979; Costa, Nigro and Danieli, 1983; Mane, Tepper and Richmond, 1983) suggesting a possible correlation with fitness. However, as we cannot exclude interference of Est-6.functions with other physiological and biochemical processes, it would be too simplistic to directly correlate the differences in enzymatic activity with the relative fitness of the genotypes. Danford and Beardmore (1980) suggested that differences in fitness among genotypes could derive from differences in the metabolic rate of the substrates added, producing different amounts of a toxic end-product. According to these authors this mechanism could account for the variation between experiments and the frequency-dependent selection observed in connection with the Est-6 polymorphism (Kojima and Yarbrough, 1967; Morgan, 1976; Birley and Beardmore, 1977; Costa and Beardmore, 1980).

In the case of methylmalonate, we suggest that the selective action could be caused by a cleavage product of the substrate (malonate) which is a powerful inhibitor of succinate dehydrogenase, and should have a negative effect on respiration. Sexual selection (Gilbert and Richmond, 1982) through allozymic differences in reproductive functions such as sperm use and mating and remating behaviour, has been demonstrated to be one of the most likely mechanisms responsible for the maintenance of the Est-6 polymorphism. Our results, concerning laboratory populations set up with forced matings, indicate that the catalytic function(s) of Esterase- 6 in ester metabolism can also be a target of selection. The results presented in this paper suggest that selection at this locus can occur at different though interacting levels. The picture of the interactions between the evolutionary forces involved in maintaining the Est-6 polymorphisms is still blurred but the data presented in this paper suggest that a range of selective mechanisms may be involved.

Acknowledgments We wish to thank Mrs M. Warren for technical help during the isolation of the inbred lines and Mrs S. Zanoli for typing the manuscript. We are grateful to $\mathrm{Dr}$ Skibinski for stimulating suggestions and helpful criticisms.
Computer simulations were carried out on the Honeywell DPS8 computer of the Centro Calcoli Numerici of the University of Pavia.

This work was partly supported by a grant from the Italian Ministry of Public Education.

\section{REFERENCES}

AllARD, R. W. 1975. The mating system and microevolution. Genetics, 79, 115-126.

ALLARD, R. W., KAHLER, A. L. AND WEIR, B. S. 1972. The effect of selection on esterase allozymes in a barley population. Genetics, 72, 489-503.

ANDERSON, P. R. AND OAKEShOT,, J. G. 1984. Parallel geographical patterns of allozyme variation in two sibling Drosophila species. Nature, 308, 729-731.

BIJLSMA, R. AND KERVER, J. M. 1983. The effect of DDT on the polymorphisms at the G6PD and PGD loci in Drosophila melanogaster. Genetics, 103, 447-464.

BIRLEY, A. J. AND BEARDMORE, J. A. 1977. Genetical composition, temperature, density and selection in an enzyme polymorphism. Heredity, 39, 133-144.

BOYER, S. H., RUCKNAGEL, D. L., WEATHERALL, D. J. ANI) WATSON-WILliAMS, F. J. 1963. Further evidence for linkage between the $\beta$ and $\delta$ loci governing human hemoglobin and the population dynamics of linked genes. Am. J. Hum. Genet., 15, 438-448.

CABRERA, V. M., GONZALES, A. M., LARRUGA, J. M. AND VEGA, C. 1983. Linkage disequilibrium in chromosome $A$ of Drosophila subobscura. Genetica, 61, 3-8.

CAVENER, D. R. AND CLEGG, M. T. 1978. Dynamics of correlated systems. IV. Multilocus effects of ethanol stress environments. Genetics, 90, 629-644.

CHARLESWORTH, B. AND CHARLESWORTH, D. 1973. A study of linkage disequilibrium in populations of Drosophila melanogaster. Genetics, 73, 351-359.

CHARLESWORTH, B., CHARLESWORTH, D., LOUKAS, M. AND MORGAN. K. 1979. A study of linkage disequilibrium in British populations of Drosophila subobscura. Genetics, 92, 983-994.

COSTA, R. ANI) BEARDMORE, J. A. 1980. Selection in a polymorphism with a rare allele. Genetica, 54, 167-172.

COSTA, R., NIGRO, L. AND DANIELI, G. A. 1983. Esterase-6 allozymes: biochemical studies of two common and one rare variant in Drosophila melanogaster. Biochem. Genet., $21,191-197$.

DANIELI, G. A. AND COSTA, R. 1977. Transient equilibrium at the Est-6 locus in wild populations of Drosophila melanogaster. Genetica, 47, 37-41.

DANFORD, N. D. AND BEARDMORE, J. A. 1979. Biochemical properties of Esterase-6 in Drosophila melanogaster. Biochem. Genet., 17, 1-22.

DANFORD, N. D. AND BEARDMORE, J. A. 1980. Selection at the esterase- 6 locus in Drosophila melanogaster by added enzyme substrates in the culture medium. Genetica, 50, $171-178$.

DF: JONG, G. ANIDSCHARLOO, W. 1976. Environmental determination of selective significance or neutrality of amylase variants in Drosophila melanogaster. Genetics, 84, 77-94.

FRANKLIN, I. R. AND LEWONTIN, R. C. 1970. Is the gene the unit of selection? Genetics, 65, 707-734.

GIBSON, J. 1970. Enzyme flexibility in Drosophila melanogaster. Nature, 255, 149-151. 
GILBERT, D. (B., RICHMOND, R. ( $\therefore$ AND SHEEHAN, K. B. $1981 a$. Studies of esterase- 6 in Drosophila melanogaster. V. Progeny production and sperm use in female inseminated by males having active or null alleles. Evolution, 35, 21-37.

GILBERT, I). G., RICHMONI), R. ( $\therefore$ AND SHEEHAN, K. B. 1981 b. Studies of Esterase-6 in Drosophila melanogaster. VII. Remating times of females inseminated by males having active or null alleles. Behav. Genet., 1/, 195-208.

GILBERT, D. G. AND RICIIMOND, R. C. 198I. Studies of Esterase-6 in Drosophila melanogaster. VI. Ejaculate competitive abilities of males having null or active alleles. Genetics, 97, 85-94.

GILBERT, D. G. AND RIC:HMOND, R. ( 1982. Studies of esterase-6 in Drosophila melanogaster. XII. Evidence for temperature selection of Est-6 and ADH alleles. Genetica, $58,109-119$.

GIRARI), P., PAlABOST, 1.. AND PETIT, (.. 1977. Enzymatic variation at seven loci in nine natural populations of Drosophila melanogaster. Biochem. Genet., 15, 589-599.

GOKHALE, D. V. AND KULLBACK, S. 1978. The information in contingency tables. M. Dekker Inc., New York.

HULME, A. 1970. The biochemistry of fruits and their products. Academic Press, London, New York

KAHLER, A. L., CLEGG, M. T. ANI) ALLARD, R. W. 1975 Evolutionary changes in the mating system of an experimental population of barley (Hordeum vulgare L.). Proc. Natl. Acad. Sci., USA, 72, 943-946.

KOJIMA, K. ANI) YARBROU(iH, K. M. 1967. Frequency-dependent selection at the Esterase-6 locus in Drosophila melanogaster. Proc. Natl. Acad. Sci., USA, 57, 645-649.

KOJIMA, K., GILLESPIE, J. AND TOBARI, Y. N. 1970. A profile of Drosophila species' enzymes assayed by electrophoresis. I. Number of alleles, heterozygosities, and linkage disequilibrium in glucose metabolizing systems and some other enzymes. Biochem. Genet., 4, 627-637.

LANGLEY, C. H., TOBARI, Y. N. AND KOJIMA, K. 1974. Linkage disequilibrium in natural populations of Drosophila melanogaster. Genetics, 78, 921-936.

LANGLEY, C. H., ITO, K. AND VOELKER, R. A. 1977. Linkage disequilibrium in natural populations of Drosophila melanogaster. Seasonal variation. Genetics, 86, 447-454.

LANGLEY, C. H., SMITH, D. B. AND JOHNSON, F. M. 1978. Analysis of linkage disequilibrium between allozyme loci in natural populations of Drosophila melanogaster. Genetics, 92, 1295-1314.

LOUKAS, M., KRIMBAS, C. B. AND VERGINI, Y. 1979. The genetics of Drosophila subohscura populations. IX. Studies on linkage disequilibrium in four natural populations. Genetics, 93, 497-523.

LOUKAS, M., KRIMBAS, C. B. AND MORGAAN, K. 1980. The genetics of Drosophila subobscura populations. XIV. Further data on linkage disequilibria. Genetics, 95, 757-768.

MACINTYRE, R. J. ANI) WRIGHT, T. R. F. 1966. Responses of Esterase-6 alleles of Drosophila melanogaster to selection in experimental populations. Genetics, 53, 371-375.

MANI, S. D., TEPPER, C. S. AND RIC.HMOND, R. C. 1983. Studies of Esterase-6 in Drosophila melanogaster. XI11. Purification and characterization of the two major isozymes. Biochem. Genet., 21, 1019-1040.

MITTILER, S. AND BENNET, J. 1962. A simple food medium that requires no live yeast with the minimum of variables. Drosophila Inform. Serv., 36, 131-132.
MORGAN, P. 1976. Frequency dependent selection at two enzyme loci in Drosophila melanogaster. Nature, 263, 765766.

MUKAI, T., METTLER, L. E. ANI) (:HIGUSA, S. 1971. Linkage disequilibrium in a local population of Drosophila melanogaster. Proc. Natl. Acad. Sci., USA, 68, 1065-1069.

mukal, T,, WAtANabi, 'T. K. AND Yamaguch1, O. 1984. The genetic structure of natural populations of Drosophila melanogaster. XII. Linkage disequilibrium in a large local population. Genetics, 77, 771-793.

MUKAI, T. ANI) VOELKER, R. A. 1977. The genetic structure of natural populations of Drosophila melanogaster. XIII. Further studies on linkage disequilibrium. Genetics, 86, 175185.

OAKESHOTT, J. G., CHAMBERS, (. K., GIBSON, I. B. ANI; WILLCOCKS, I). A. 1981. Latitudinal relationships of Esterase-6 and Phosphoglucomutase gene frequencies in Drosophila melanogaster. Heredity, 47, 385-396.

POWELl, J. R. AND ANIDIFLKOVIC, M. 1983. Population genetics of Drosophila amylase. IV. Selection in laboratory populations maintained on different carbohydrates. Genetics, 103, 675-689.

RICHMOND, R. C., GIIBER', 1). G., SHEEMAN, K. B., GROMKO, M. H. AND BUTTERWORTH, F. M. 1980. Esterase-6 and reproduction in Drosophila melanogaster. Science, 207, 1483-1485.

RICHMONI), R. C. AND SENIOR, A. 1981. Studies of Esterase-6 in Drosophila melanogaster. IX. Kinetics of transfer to females, decay in females and male recover. $J$. Insect. Physiol., 21, 849-853.

TEPPER, C. S., RICHMOND, R. C., TERRY, A. L. AND SENIOR, A. 1982. Studies of esterase-6 in Drosophila melanogaster. $\mathrm{XI}$. Modification of esterase- 6 activity by unlinked genes. Genet. Res. Camb., 40, 109-125.

TEPPER, C. S., TERRY A. L., HOLMES, J. E. AND RICHMOND, R. C. 1984. Studies of esterase-6 in Drosophila melanogaster. XIV. Variation of esterase- 6 levels controlled by unlinked genes in natural populations. Genet. Res. Camb., 43, 181190.

THORSBY, E. 1974. The human major histocompatibility system. Transplant. Rev., 18, 51-129.

TREAT, L. G., DOANE, W. W. AND MACINTYRE, R. J. 1980. Biochemical loci of the fruit fly (Drosophila melanogaster). In Genetic Maps, vol. I, (Ed.) S. J. O'Brien. N.I.H., Bethesda.

TRIANTAPHYLLIDIS, ( $(.1)$, , SCOURAS, Z. (i., PANOURGIAS, J. N. ANI IOANNIDIS, G. C. 1982. Allozyme variation in Greek wild populations of Drosophila melanogaster and $D$. simulans along a North-South gradient. Genetica, 58, 129136.

TRIPPA, (i., DANIELI, (`. A., (COSTA, R. ANI) SCOZZARI, R, 1978. Phosphoglucomutase (PGM) and Esterase-6 (Est-6) alleles in Drosophila melanogaster: an attempt to detect linkage disequilibrium. Genetica, 49, 225-227.

WIILS, C. AND NICHOIS, L. 1971. Single gene heterosis revealed by inbreeding. Nature, 233, 123-125.

WILLS, C.. PHELPS, J. ANI) FERGUSON, R. 1975. Further evidence for selectivc differences between isoalleles in Drosophila. Genetics, 79, 127-141.

WRIGHT, T. R. F. 1963. The genetics of an esterase in Drosophila melanogaster. Genetics, 48, 787-801. 